\title{
Incorporating Uncertainty into Backward Erosion Piping Risk Assessments
}

\author{
Bryant A. Robbins ${ }^{1, a}$, Michael K. Sharp ${ }^{1}$ \\ ${ }^{1}$ U.S. Army Engineer Research and Development Center, Vicksburg, MS, USA
}

\begin{abstract}
Backward erosion piping (BEP) is a type of internal erosion that typically involves the erosion of foundation materials beneath an embankment. BEP has been shown, historically, to be the cause of approximately one third of all internal erosion related failures. As such, the probability of BEP is commonly evaluated as part of routine risk assessments for dams and levees in the United States. Currently, average gradient methods are predominantly used to perform these assessments, supported by mean trends of critical gradient observed in laboratory flume tests. Significant uncertainty exists surrounding the mean trends of critical gradient used in practice. To quantify this uncertainty, over 100 laboratory-piping tests were compiled and analysed to assess the variability of laboratory measurements of horizontal critical gradient. Results of these analyses indicate a large amount of uncertainty surrounding critical gradient measurements for all soils, with increasing uncertainty as soils become less uniform.
\end{abstract}

\section{Introduction}

Internal erosion refers to various processes that cause erosion of soil material from within or beneath a water retention structure such as a dam or levee. With regard to flood risk, internal erosion is an issue of significant concern. Approximately half of all historical dam failures have been attributed to internal erosion [1]. While internal erosion risk can be reduced through the use of well-designed filters and drains, modifying the entirety of existing infrastructure to meet modern filter standards is not economically feasible. Therefore, it is of utmost importance to be able to assess the likelihood of internal erosion occurring on existing infrastructure such as dams, levees, and canals.

Internal erosion processes can be subdivided into four broad categories: concentrated leak erosion, backward erosion piping (BEP), internal instability, and contact erosion [2]. This paper will discuss solely BEP, which accounts for approximately one third of all internal erosion related dam failures [1], [3]. For discussion on the other types of internal erosion, the authors suggest reviewing Bonelli et al. [4].

The process of BEP is illustrated in Figure 1. For BEP to occur, it is necessary to have an unfiltered seepage exit through which soil can begin eroding. As filters and drains are rare along levee systems in the United States, the seepage exit condition is usually unfiltered. This is evident by the numerous sand boils that occur along the U.S. levee systems during each flood [5]. A sand boil is a small cone of deposited soil that occurs concentrically around a concentrated seepage exit, as shown in Figure 1. The presence of sand boils indicates that the process of BEP has initiated at a particular site. Whether the BEP process continues, ultimately leading to structural failure, depends upon numerous conditions being met (roof support, sufficient hydraulic gradients for erosion propagation, and unsuccessful human intervention). Estimation of the probability of failure due to BEP should consider all of these factors, as well as the uncertainty surrounding them. The focus of this paper is on improving how uncertainty regarding critical gradients for BEP is incorporated into risk assessments, with particular emphasis on methods used in the U.S. While the work reported is a simple extension of the groundbreaking work of Schmertmann and Sellmeijer ([6] \& [7]), the authors hope that the simple portrayal of uncertainty presented leads to the objective quantification of uncertainty in BEP risk assessments.

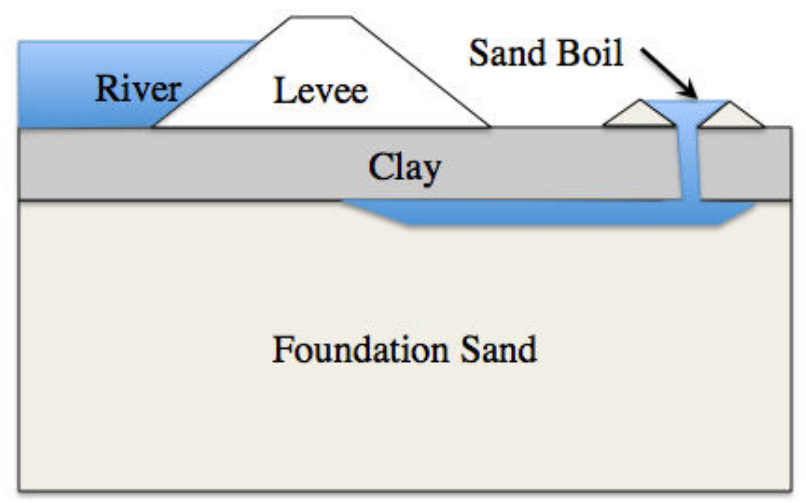

Figure 1. Illustration of BEP progressing beneath a levee.

\footnotetext{
a Corresponding author: Bryant.A.Robbins@usace.army.mil
} 


\section{Literature Review}

In order to discuss uncertainty in BEP risk assessments, it is necessary to understand both how BEP is currently assessed and how uncertainty is currently considered. The following sections provide a brief review of current assessment methods and previous work that has quantified uncertainty regarding critical gradients.

\subsection{BEP Assessment Methods}

In the U.S., the most common means of assessing the probability of BEP is through the use of event trees, as discussed by USACE \& USBR [8] and Goodarzi [9]. In an event tree, the process of BEP is subdivided into a sequence of events (nodes), all of which must occur for failure to ensue. A simple event tree is illustrated in Figure 2. Each node in the event tree is assumed to be conditional on only the prior node such that the probability of BEP leading to failure can be calculated as the product of the nodal probabilities. The probability of each individual node occurring is assessed through a combination of engineering judgment and analyses results. For example, the probability of BEP initiation may be assessed through probabilistic underseepage analyses such as those developed by Rice and Polanco [10] or Wolff [11]. Judgment is used to interpret the analyses results and determine the best estimate of the probability of initiation. The probability of an unfiltered exit may be set to a value of 1.0 for many levee scenarios. For structures with filters, the probability may vary, depending on the adequacy of the designed filter and drain. The probability of roof support existing depends on the geologic conditions at a site.

$\%$ Water level at or above threshold level

$\%$ Initiation: Erosion starts

\% Continuation: No filter, roof support, erodible soil

$\%$ Progression: Gradients above critical value

$\%$ Unsuccessful detection and intervention

$\%$ Breach

Figure 2. Simplified event tree for BEP evaluation.

In the example event tree, progression is evaluated by comparing the expected hydraulic gradients in the field to a critical gradient value. This is one of the more difficult estimates to make due to the numerous, and often conflicting, methods that exist in the literature for estimating the critical gradients. Empirical estimates based on failure case histories have been made ([12], [13]). More recently, Sellmeijer ([7], [14]) and Schmertmann [6] have developed methods for estimating critical gradients. It is common for all methods to be used on a particular project, with the final probability estimate made by weighting the methods based on project applicability. For a thorough discussion of the various methods, as well as factors that influence critical gradient measurements, refer to [15].

\subsection{Critical Gradients and Uncertainty}

Numerous authors have quantified the uncertainty surrounding the critical conditions for BEP. Schmertmann [6] made an estimate of the variance associated with the conditional distribution of critical point gradients $\left(\mathrm{i}_{\mathrm{pmt}}\right)$, as well as an estimate of the contribution to the total variance made by each covariate (e.g. density, geometry, grain size). It is unclear how the estimates of variance were made; and, in the authors' experience, it is not common for these estimates of variance to be used in practice. Lopez de la Cruz et al. [16] made estimates of both the distribution type and the distribution parameters for the input parameters into the adjusted Sellmeijer model [14], based upon a calibration to laboratory and field scale test results. Schweckendiek [17] and Roscoe and Hanea [18] have demonstrated how Bayesian updating can be used to obtain posterior estimates of the Sellmeijer covariate distributions for a particular site. Neither the covariate distributions nor Bayesian updating procedures have gained widespread use for estimating conditional probability distributions in the U.S.

It is the authors' opinion that the results of the studies above have not been widely implemented in practice because their origins and applicability are ambiguous to practitioners. The remainder of this paper focuses on providing a transparent and simple quantification of uncertainty surrounding the critical point gradients used by Schmertmann [6]. Focus was directed towards this method as it is one of the most common methods used in the U.S.

\section{Estimating Critical Point Gradients}

\subsection{Current Practice}

Schmertmann [6] proposed the linear relationship shown in Figure 3 as a means of estimating the critical point gradients for a soil as a function of the particle size distribution (specifically the uniformity coefficient) for cases in which laboratory test results are not available. In practice, laboratory flume tests are rarely conducted to measure the critical gradients in the field, and the linear relationship proposed by Schmertmann is the primary source for determining critical gradient values for risk assessments. It must be recognized that the critical point gradient values shown in Figure 3 are study averages. For example, the point representing all Reid Bedford sand test results conducted by [19], [20], and [21] is plotted at a $\mathrm{Cu}$ of 1.5 and an $\mathrm{i}_{\text {pmt }}$ of 0.152 . This single data point shown in Figure 3 is the average value obtained from 14 individual laboratory tests. It also must be recognized that the point gradients shown are corrected as described in [6] in an attempt to remove the influence of all covariates other than uniformity coefficient (e.g. density, anisotropic permeability, seepage geometry, grain size, seepage path inclination, and scale). Table 1 indicates the covariate reference values to which the laboratory tests were corrected. 


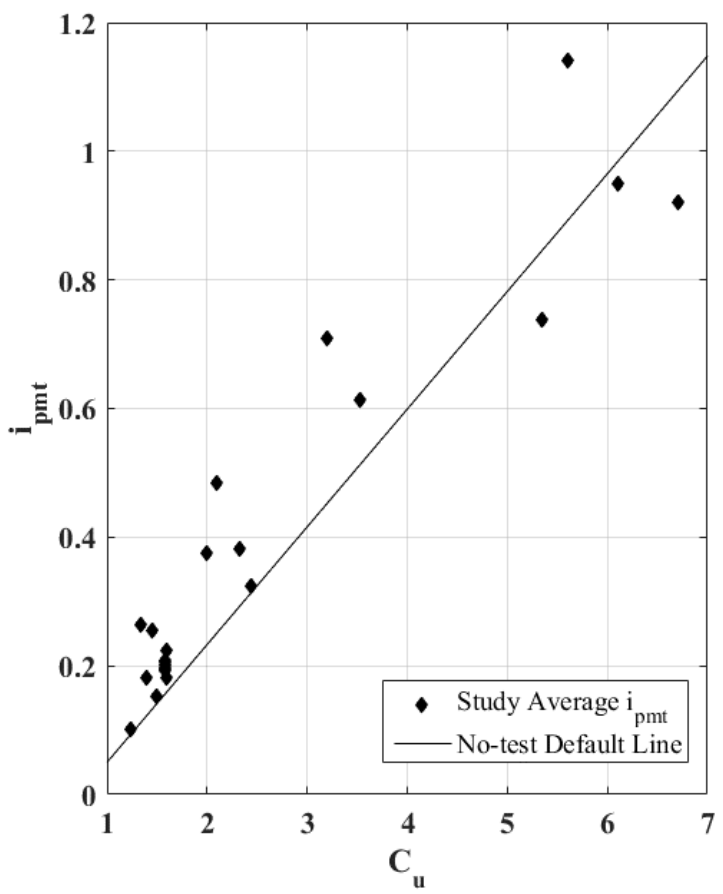

Figure 3. Suggested relationship for determining the critical point gradient as a function of $\mathrm{C}_{\mathrm{u}}$ (from [6]). Points represent study averages of critical point gradient.

\begin{tabular}{|c|c|}
\hline Variable & Reference Value \\
\hline Seepage Length & $1.52 \mathrm{~m}$ \\
\hline Layer Depth & $0.30 \mathrm{~m}$ \\
\hline Layer Width & $0.30 \mathrm{~m}$ \\
\hline Grain Size $\left(\mathrm{d}_{10}\right)$ & $0.20 \mathrm{~mm}$ \\
\hline $\mathrm{K}_{\mathrm{h}} / \mathrm{K}_{\mathrm{v}}$ & 1.5 \\
\hline Relative Density & $60 \%$ \\
\hline Seepage Path Inclination & 0 degrees \\
\hline
\end{tabular}

Table 1. Reference values used for adjusting the laboratory flume test results to critical point gradient values (see [6] for further details).

When using Figure 3 (or the equivalent figure from [6]), to estimate critical point gradients, it is necessary to correct for all factors described by Schmertmann using the reference values in Table 1 to arrive at comparable point gradient values. Neglecting to adjust the values to equivalent point gradients will yield erroneous results; the magnitude of these errors has been shown to be as large as 100 percent for factors related to soil density and problem geometry [15].

\subsection{Quantifying Uncertainty}

While Figure 3 is quite useful, it is difficult to estimate the uncertainty in the critical point gradient because study averages are presented. In order to examine the uncertainty in greater detail, the individual laboratory test results from each experimental series must be examined. The authors have compiled all of the laboratory test results from [19]-[25]. It was difficult to establish the exact number of tests in each experimental series from references [22] and [23]. However, [26] has provided a very thorough overview of the experiments conducted by de Wit and Silvis. This overview was used to determine the individual tests conducted for each experimental series conducted by de Wit and Silvis. Mueller-Kirchenbauer conducted more tests than documented in [25]. However, for the sake of consistency with [6], only the single test reported in [25] was considered. In total, 110 laboratory piping tests were found in the references previously mentioned. Of these, 9 of the piping tests were right censored (did not fail) [19, 21]. For all of the tests, the test results were corrected using the correction factors provided in [6] to correct the individual test results to the common reference values in Table 1.

The corrected, individual laboratory critical point gradients obtained from the 110 tests found in the literature are plotted in Figure 4. For comparison purposes, the no-test default line proposed by Schmertmann and the best-fit median line are plotted as well. From visual observation, it is seen that the no-test default line (dashed) proposed by Schmertmann [6] more closely approximates a lower bound than an average trend for low values of uniformity coefficient.

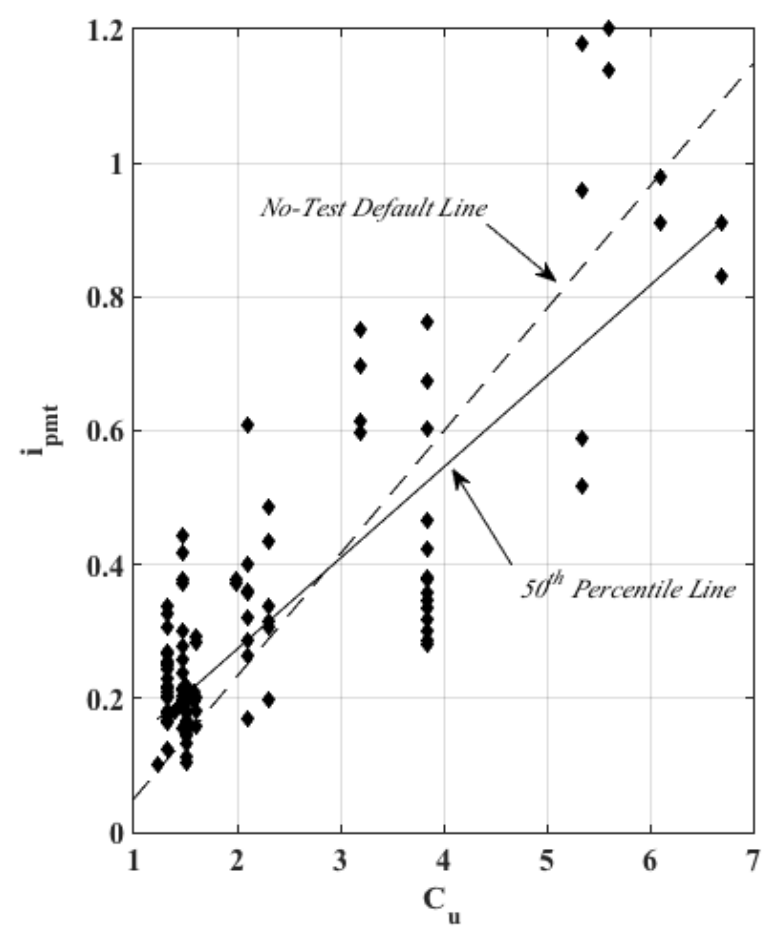

Figure 4. Suggested relationship for determining the critical point gradient compared to the best fit, median line of all test results. Points represent individual laboratory tests.

Visual observation of Figure 4 also indicates that the individual laboratory test points exhibit increasing variance as the uniformity coefficient increases. This 
non-constant variance, called heteroscedasticity, indicates that ordinary least squares (OLS) linear regression is not a suitable means of estimating the uncertainty surrounding the expected value (mean trend). OLS will not capture the heteroscedasticity due to the constant variance, Gaussian residual models typically associated with linear regression. Transformations (e.g. log transforms when dealing with exponential data) are commonly used to transform the data to a distribution of a particular form such that OLS regression techniques can be used to estimate the conditional probability distribution of the dependent variable. Another approach to capturing the heteroscedasticity is the use of generalized linear regression models, which attempt to model the changing variance across the range of covariates. In order to keep the results as simple and as visual as possible, the data quantiles were used as estimates of the conditional probability distribution.

The $n^{\text {th }}$ quantile of a sample of data is the value in the data set for which the proportion $n$ of the sample is lower, and the proportion $(1-n)$ is higher. As the size of the sample increases, such that the empirical probability density function (PDF) of the data more closely approximates the underlying probability distribution, the $n^{\text {th }}$ quantile approaches the $n^{\text {th }}$ percentile of the underlying probability distribution. For small samples, the empirical quantiles will exhibit less variance than the equivalent percentiles due to the influence of the sample size. For this particular application, the consequences of this are minor compared to the influence of the many correction factors used in arriving at the estimates of critical point gradients for each test. For this reason, the authors consider the quantiles to be an adequate estimate of the conditional probability distribution of critical point gradients.

To estimate the quantiles of the individual laboratory test data, first order quantile regression was performed. In other words, a linear equation was fit through the data such that, for each $n^{\text {th }}$ quantile, an $n^{\text {th }}$ fraction of the data lies below the line and a (1-n) fraction of the data lies above the line. For an excellent (and quite humorous) introduction to quantiles and quantile regression, the authors recommend reviewing [27]. Quantile regression was used to estimate each quantile between the $10^{\text {th }}$ and the $90^{\text {th }}$ quantiles in increments of 10 percent. While statistically incorrect to include the censored observations in the regression, inclusion results in a conservative bias and still provides useful information. For this reason, and given the sparse data at high values of uniformity coefficient, the censored data was included in the regression analyses. The resulting quantiles are plotted in comparison to the data in Figure 5. The 6 observations obtained from [24] are distinguished from the rest of the data as these observations were obtained from a different testing configuration and exhibit more variability than the other test series. While these observations were included to provide a direct comparison to [6], they should be carefully evaluated when using the results of this study.

From the linear quantiles plotted in Figure 5, it is readily seen that the variance in the conditional distribution of the critical point gradient increases with increasing uniformity coefficient. It is also observed that the spread in the data is quite large. At a uniformity coefficient of 2 , the difference between the $i_{\text {pmt }} 90^{\text {th }}$ and $10^{\text {th }}$ percentiles is 0.26 . At a uniformity coefficient of 6 , the difference is 0.82 . In both cases, the spread in the distribution is large and should be considered in risk assessments. Figure 5 can readily be used to inform estimates of the conditional distribution of critical point gradients for estimating the probability of BEP progression in the appropriate node of an event tree analysis.

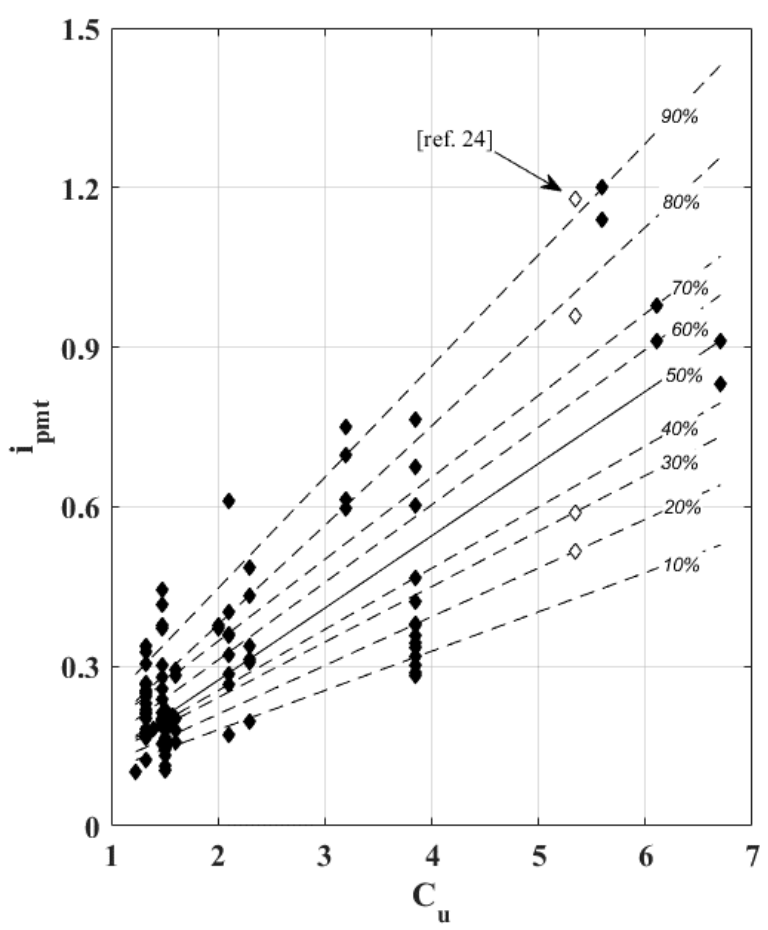

Figure 5. Critical point gradients from individual laboratory tests and best fit quantile regression lines for the $10^{\text {th }}$ to $90^{\text {th }}$ quantiles. Open points are from a different testing configuration [24] than other points.

\section{Discussion}

An analysis of the uncertainty, or spread, in the conditional distribution of critical point gradients for BEP was conducted, yielding the resulting Figure 5. This figure can be used to make estimates of the probability of $\mathrm{BEP}$ progression in risk assessments. In order to use this information to estimate BEP probabilities, the gradients in the field at a particular site must be corrected using the corrections in [6] to equate the field conditions to the reference values for all covariates provided in Table 1 . Without performing these corrections, the probabilities inferred from Figure 5 will not be correct.

As an example, consider a levee foundation that is being assessed for BEP progression. Finite element analyses determines that the minimum point gradient along the potential piping path is 0.16 . In order to compare this value to Figure 5, the field value must be corrected to the laboratory scale, grain size, density, and path inclination reference values in Table 1. After 
applying all correction factors, the point gradient in the field is estimated to be 0.21 when adjusted to the reference values. The best estimate of the uniformity coefficient along the piping path is a value of 2 . From Figure 5 for this example, we see that the field conditions correspond to the $20^{\text {th }}$ percentile of the critical point gradient data. As such, 20 percent of samples tested should be expected to fail at the gradient experienced in the field, or there is a 20 percent probability of BEP progression.

The above analysis can be compared to the assessment of critical point gradient uncertainty presented in [6] by using the suggested coefficient of variation of 0.25 as the model uncertainty surrounding the no-test default line. For the coefficient of uniformity of 2 in the example, the no- test default line predicts a mean critical point gradient of 0.23 . Using a lognormal distribution, the probability of progression for the point gradient in the field $(0.21)$ is determined to be 38 percent. The slightly higher probability obtained is likely due to the no-test default line being a lower bound of the average values for low values of uniformity coefficient. However, given the relative uncertainty in all aspects of risk analyses, the difference in probability of progression obtained from the quantile regression and [6] is negligible for the provided example.

\section{Conclusions}

A compilation of laboratory measurements of critical point gradients for backward erosion piping is presented. The probability distribution of critical point gradients is characterized as a function of uniformity coefficient through first order quantile regression on the sample of 110 laboratory test results. Results of these analyses indicate a large amount of uncertainty surrounding critical gradient measurements for all soils, with increasing uncertainty as soils become less uniform. The results of this study can be used in risk assessments to estimate the probability of progression for backward erosion piping.

\section{Acknowledgements}

The authors are very thankful for the numerous reviews of this paper. In particular, review comments and discussion provided by John Schmertmann were incredibly helpful for understanding previous work and deciding how to portray the information in this paper. The authors would also like to acknowledge the comments and suggestions provided by Greg Karlovitz, Minal Parekh, Scott Shewbridge, Tim O'Leary, and Tom Terry.

Permission to publish was granted by Director, Geotechnical and Structures Laboratory.

\section{References}

[1] M. Foster, R. Fell, and M. Spannagle, "The statistics of embankment dam failures and accidents," Can. Geotech. J., vol. 37, no. 10, pp. 1000-1024, 2000.

[2] ICOLD, "Bulletin 164 - Internal erosion of existing dams, levees and dikes, and their foundations. Volume 1: Internal erosion processes and engineering assessment," 2015.

[3] K. S. Richards and K. R. Reddy, "Critical appraisal of piping phenomena in earth dams," Bull. Eng. Geol. Environ., vol. 66, no. 4, pp. 381402, Jul. 2007.

[4] S. Bonelli, Erosion in Geomechanics Applied to Dams and Levees. Hoboken, NJ, USA: John Wiley \& Sons, Inc., 2013.

[5] M. E. Glynn and J. K. Kuszmaul, "Prediction of Piping Erosion Along Middle Mississippi River Levees--An Empirical Model (Sept 2004, Revised 2010)," Vicksburg, 2004.

[6] J. H. Schmertmann, "The No-Filter Factor of Safety Against Piping Through Sands," in Judgment and Innovation, F. Silva and E. J. Kavazanijian, eds. American Society of Civil Engineers, 2000, pp. 65-133.

[7] J. B. Sellmeijer, On the Mechanism of Piping under Impervious Structures, Delft University of Technology, 1988.

[8] USACE and USBR, "Internal erosion risks," in Best Practices in Risk Assessment for Dams and Levees, 2012 ed., Denver, CO, 2012.

[9] E. Goodarzi, "Estimating probability of failure due to internal erosion with event tree analysis," Electron. J. Geotech. Eng., vol. 15, pp. 935-948, 2010.

[10] J. D. Rice and L. Polanco, "Reliability-based underseepage analysis in levees using a response surface-monte carlo simulation method," $J$. Geotech. Geoenvironmental Eng., 2012.

[11] T. F. Wolff, Evaluating the reliability of existing levees, Vicksburg, MS, USA, U.S. Army Engineer Research and Development Center, 1994.

[12] E. W. Lane, "Security from under-seepage masonry dams on earth foundations," Trans. ASCE, vol. 100, no. 1, pp. 1235-1272, 1935.

[13] W. G. Bligh, "Dams, barrages and weirs on porous foundations," Eng. Rec., vol. 64, no. 26, pp. 708-710, 1910.

[14] H. Sellmeijer, J. López, D. Cruz, V. M. van Beek, and H. Knoeff, "Fine-tuning of the backward erosion piping model through small-scale, medium-scale, and IJkdijk experiments," Eur. J. Environ. Civ. Eng., vol. 15, no. 8, pp. 1139-1154, 2011.

[15] B. A. Robbins and V. M. van Beek, "Backward erosion piping: A historical review and discussion of influential factors," in ASDSO Dam Safety, New Orleans, LA, USA 2015, pp. 1-20.

[16] J. Lopez de la Cruz, E. Calle, and T. Schweckendiek, "Calibration of piping 
assessment models in the Netherlands," in International Symposium on Geotechnical Risk and Safety, 2011, pp. 587-595.

[17] T. Schweckendiek, On Reducing Piping Uncertainties: A Bayesian Decision Approach, Delft University of Technology, 2014.

[18] K. Roscoe and A. Hanea, "Bayesian networks in levee system reliability," in 12th International Conference on Applications of Statistics and Probability in Civil Engineering, no. 1., 2015.

[19] J. H. Schmertmann, Report on Flume Tests for Piping and Scour Erosion of HL-2 Sands, 1995.

[20] F. Townsend, J. H. Schmertmann, T. J. Logan, T. J. Pietrus, and Y. W. Wong, "An Analytical and Experimental Investigation of a Quantitative Theory for Piping in Sand," Gainesville, FLorida, 1981.

[21] F. Townsend and J.-M. Shiau, Analytical and Experimental Evaluation of Piping and Filter Design for Sands, Gainseville, FL, 1986.

[22] J. M. de Wit, Research Report on Sand Boil Model Tests, Delft, Netherlands, 1984.

[23] J. Weijers and J. Sellmeijer, "A new model to deal with the piping mechanism," Filters in Geotech. Hydraul. Eng., pp. 349-355, 1993.

[24] I. Kohno, M. Nishigaki, and Y. Takeshita, "Levee failure caused by seepage and preventetive measures," Nat. Disaster Sci., vol. 9, no. 2, pp. 55-76, 1987.

[25] H. Muller-Kirchenbauer, M. Rankl, and C. Schlotzer, "Mechanism for regressive erosion beneath dams and barrages," in Filters in Geotechnical and Hydraulic Engineering, 1993, pp. 369-376.

[26] V. M. van Beek, Backward Erosion Piping: Initiation and Progression, Technische Universiteit Delft, 2015.

[27] R. Koenker and K. Hallock, "Quantile regression: An introduction," J. Econ. Perspect., vol. 15, no. 4, pp. 43-56, 2001. 